\title{
Myringotomy with Ear Tube Placement
}

National Cancer Institute

\section{Source}

National Cancer Institute. Myringotomy with Ear Tube Placement. NCI Thesaurus. Code C70906.

A surgical procedure where an incision is made through the eardrum, and a plastic or metal tube is inserted. 